\title{
Enterprise Architecture Design Strategies for UGK Using TOGAF ADM
}

\author{
Julius Galih Prima Negara $^{1 *}$, Andi Wahju Rahardjo Emanuel ${ }^{1}$ \\ ${ }^{1}$ Magister Teknik Informatika, Universitas Atma Jaya Yogyakarta, Yogyakarta 55281, Indonesia \\ "Corresponding author. Email: galihprima21@gmail.com
}

\begin{abstract}
The application of Enterprise Architecture (EA) in university is a long endeavour that must be carried out by higher education institutions. The solution to dealing with these challenges is good EA planning in accordance with the guiding model and making it a comprehensive view of the completion of an enterprise framework initiative. The harmony between the organization's business processes and information technology, and selection of the right EA framework will improve performance and will quickly make simple architectural development in future development in accordance with institutional needs. TOGAF ADM offers a comprehensive framework and is able to meet organizational needs related to information management needs. EA modelling in the academic process at Gunung Kidul University produced blueprints of business architecture, data, applications, and technology. In this paper several stages are written in accordance with the TOGAF ADM starting from preliminary, gap analysis at each architectural stage.
\end{abstract}

Keywords: Enterprise Architecture, university, TOGAF ADM

\section{INTRODUCTION}

Gunung Kidul University abbreviated as UGK or UGKY is a private university located in the city of Wonosari, Kab. Gunung Kidul, Yogyakarta Province. The university was established in 2001 and has a "Tri Dharma perguruan tinggi" use this as a guideline in the organization life. The university has organized a simple office system. UGK already uses computers for its office activities but does not yet have an integrated information system, computer connections between departments. Job optimization is expected to be maximized with the application of enterprise architecture.

Information system (IS) is a combination of users, hardware, software, communication networks and data resources that collect, change and disseminate information in an organization [1]. In an organization, information systems are used to communicate with others using devices (hardware), stages and instructions for processing information (software), communication networks (networks), and data stored (stored data).

Enterprise Architecture can be seen as a blueprint to optimize resources in the IT environment, thus supporting existing business functions. Whereas, some definitions of Enterprise Architecture (EA), are:

a. It is a basic strategic information asset, which defines the mission, information and technology needed to achieve the organization's mission, and the transition processes to implement new technologies in responding to the mission of change needed [2].

b. EA is a statement of how an organization starts and produces a good order about the implementation of IT and business processes to win competition [1]. c. A collection of principles, methods, and models that are reasonable that are used to design and realize an enterprise organizational structure, business processes, information systems, and infrastructure.

TOGAF (The Open Group Architecture Framework) is a framework for developing an EA. Starting from Technical Architecture for Information Management (TAFIM) in the United States Department of Défense, the framework was adopted by the Open Group in the mid-1990s. The first TOGAF specification was introduced in 1995. TOGAF is the result of the development of the Open Group forum which is a collaboration forum between vendors and users. The last TOGAF document launched was TOGAF version 9.1 (TOGAF 9.1) [3] [4].

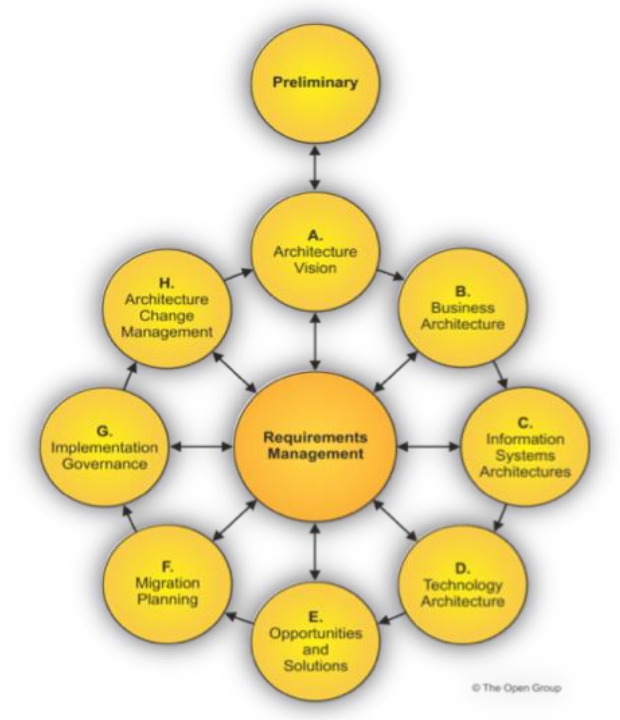

Figure 1 Architecture Development Management

The process in implementing TOGAF ADM can flexibly adjust the organization's needs. Figure 1 shows the ADM 
phase and iteration. TOGAF provides detailed methods for building, managing, and implementing EAs and information systems called the Architectural Development Method (ADM), this is a collaboration between several practitioners in the Open Group Architecture Forum organization. ADM is a general method that contains a series of activities that present the development of each ADM phase and the architectural models used and created during the EA development stage [5] [6].

There are four architectural domains commonly accepted by TOGAF as a subset of EAs as a whole, including [7]:

a. Business Architecture. This architecture describes how business processes to achieve organizational goals.

b. Data Architecture. This architecture is a description of how to store, manage and access enterprise data.

c. Application Architecture. This architecture is a description of how the application is designed and interacts with other applications.

d. Technology Architecture. This architecture is a description of infrastructure

e. Hardware and software that supports applications and their interactions.

\section{METHOD}

This research looks at the EA blueprint from the point of view of service and academic process business processes at UGK to support IT implementation. Good flexibility of an IT infrastructure is a priority in the course of any business environment. Therefore this stage is carried out from observation. The stages in this study begin from extracting background problems, then searching and retrieving data (literature studies, observations, and interviews) at the UGK. After searching for the required data, the next process performs EA modelling using the TOGAF ADM framework to produce EA blueprints (business architecture, data, applications, and technology).

Based on the steps in architectural modelling using TOGAF, the nine steps that must be taken are [8]:

a. Preliminary

At this stage, it defines the preparation of activities needed to meet the organizational architecture framework, specifications and organizational principles [9].

b. Phase A: Architecture Vision

At this stage, it defines the scope, identifies stakeholders, and creates an architectural vision [6].

c. Phase B: Business Architecture

At this stage develop a business architecture to support the architectural vision. Identify baselines, target designs, and gap analysis on business architecture [3].

d. Phase C: Information Systems Architectures At this stage develop an information system architecture (data and applications) to support business architecture. Identify baselines, target designs, and gap analysis on information system architecture [8].

e. Phase D: Technology Architecture

At this stage develop a technology architecture to support information system architectures. Identify baselines, target designs, and gap analysis of technology architecture [10].

f. Phase E: Opportunities \& Solutions

At this stage, evaluation and selection of implementation alternatives are carried out, identifying assessments primarily related to financing, and summarizing the benefits of the implementation plan and strategy [11].

g. Phase F: Migration Planning

At this stage, the order of projects is based on priorities including an assessment of the dependence, costs, and benefits of the migration project. The priority sequence will be the basis for project implementation [12].

h. Phase G: Implementation Governance

At this stage compile recommendations for each project implementation, draw up an architectural contract and carry out the entire implementation process, establish the implementing organization for the system implementation process, ensure the suitability of the project implementation with the desired architecture [13].

i. Phase H: Architecture Change Management At this stage, it establishes a change management architecture process for new EAs that have been implemented, continuously monitors technological developments and organizational changes and determines whether the next EA development cycle will be carried out [14].

Requirements Management, evaluate the process of desired architecture management through ADM [15].

\section{RESULTS AND DISCUSSION}

EA modelling uses the TOGAF ADM framework to support information systems in the academic process at UGK which include business architecture, data architecture, application architecture, and technology architecture. The process carried out in EA modelling using the TOGAF ADM stages includes the Preliminary Phase, Architectural Vision (Architecture Vision), Business Architecture (Business Architecture), Information System Architecture (Information System Architecture), and Technology Architecture.

\subsection{Preliminary}

At this stage, the author conducts an initial review to create the scope and also describe the architectural principles desired by the UGK. The author collects data by conducting interviews as a basis for scope in architectural work. At the time of the interview, there were found several obstacles to data collection, processing, and presentation of information or organizational data. This is due to the fact that since the establishment of this university until interviews were conducted, it was not prepared for EA or just an information system. Even the financial payment system is only done manually recorded in a traditional receipt, and students only get a handwritten receipt. Based on interviews, discussions, 


\subsection{Architecture Vision}

and direct review of the location, and people responsible for the management of Information Technology (IT), as well as management representatives from the UGK, it can identify a number of current information system problems, including application system and Computer Network Infrastructure.

The absence of an application system platform that is helpful to the overall process in each part/unit, so that the existing operational process is not optimal. Integration between applications. In general, the UGK information system has not been structured in a systematic and integrated integration architecture framework as well as its security. There is no integration of authentication and authorization of users who access information systems, security login systems. The lack of communication and collaboration between applications in the form of data exchange and shared use of web services belonging to an application to run functional applications. There is no integration platform in the existing IT architecture.

There is no optimal bandwidth management, and there is no implementation of a web content filter to support healthy internet behaviour. They still do not use network security devices located at the gateway that can ward off viruses. The capacity of the existing RAM server is still not fully utilized, thus inhibiting the processing of memoryconsuming data. There is no network monitoring device that facilitates computer network management processes, computer network troubleshooting, and maintenance. Access Point (AP) which is used to support the performance of wireless data access, there are those who have not used $802.11 \mathrm{n}$ type wireless which supports transfer bandwidth of up to $300 \mathrm{Mbps}$, and there is no wireless controlling implementation for AP management.

Identification of the Principles of Architecture. The principle of architecture is a set of principles statements related to architectural work. The UGK has not yet had architectural principles documents, such as business architecture principles, data, applications, and technology that can be used for EA development. The importance of an architectural principle guiding the development of EA, UGK was inspired to adopt the architectural principles of the TOGAF ADM framework.

After confirming and discussing the principles recommended by the TOGAF ADM framework, with UGK and LPIK Management, six business principle agreements were obtained, namely (1) principle position, (2) Maximizing benefits/services for stakeholders, (3) Information management is business of all stakeholders, (4) Guaranteed business continuity, (5) In accordance with applicable regulatory/legal policies, and (6) Responsibility for implementing IT. The principle of data is (1) Data is an asset, (2) Data can be accessed together (shared), (3) Data can be accessed, and (4) Data security is guaranteed. The application principles are (1) Technology independence, (2) Ease of use, (3) Service-oriented, and (4) Application systems using the concept of ERP (Enterprise Resources Planning). And technological principles are (1) Adaptive technology design, (2) Existing infrastructure must be standard (interoperability), (3) Scalability, Availability, Backup, and Archival, and (4) Level of security.
The stakeholders do not have an IT background and do not know deeply about the concepts and products of IT services and their benefits. Therefore, an architecture that can explain and be understood by all stakeholders is high-level. Based on the interviews we can conclude the architectural vision as follows: "Providing an EA that is safe, easy to use, and adaptive with service-oriented to stakeholders, and uses an ERP (Enterprise Resources Planning) application system by focusing on cost savings". The vision of Business Architecture: Providing services for all stakeholders using information technology that can bridge all existing business processes, so they can interact in an integrated, collaborative, effective and efficient manner. The vision of Data Architecture: Using the best data and information management practices and valuing data and information as strategic assets. The vision of Application Architecture: Developing and integrating software systems using the concept of ERP (Enterprise Resources Planning) with easy use, and sharing services to user needs. The vision of Technology Architecture: Distributing IT infrastructure that supports the organizational vision for information management, application development, and business process management, as well as the IT infrastructure provided using a cost-effective approach.

\subsection{Service an Business Process}

The following are the baseline Business Process condition of UGK and the target (Figure 2 and figure 3).

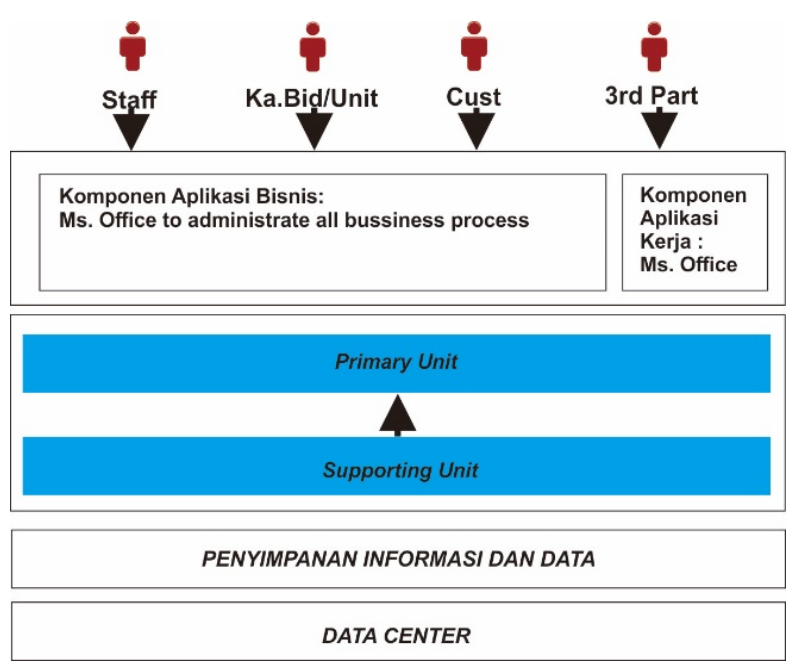

Figure 2 Business architecture baseline 


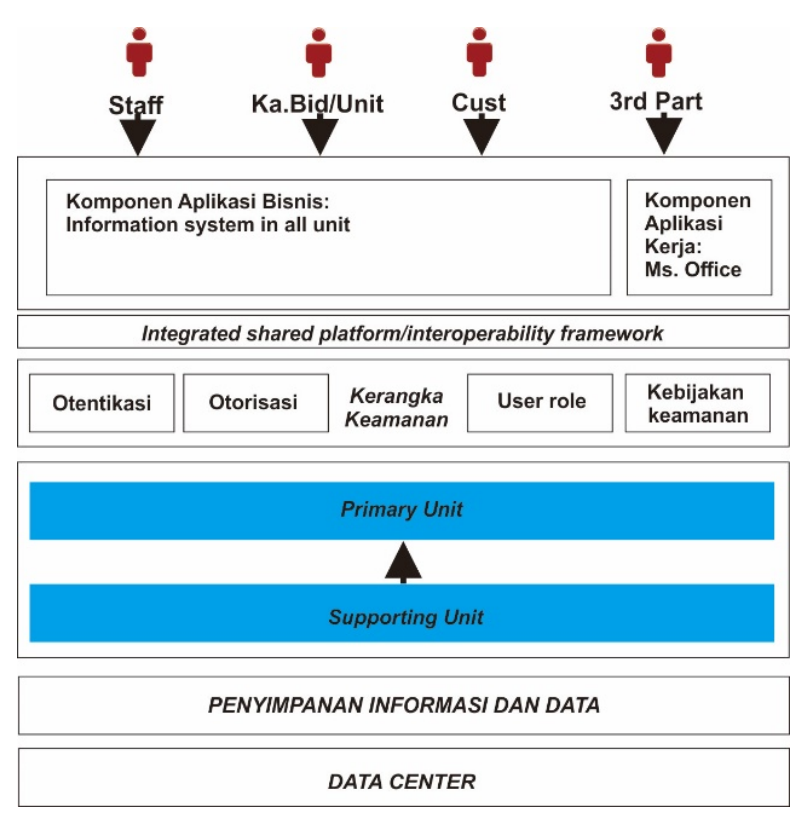

Figure 3 Business architecture target

There is a list of gap analysis that has been documented, gap analysis table can be obtained from the author. At previous stage and next each stage offered by Togaf ADM, this institution can directly implement the strategic planning offered. This is due to the fact that this new institution has not implemented a fully integrated computerized system, based on findings during interviews and observations.

\section{CONCLUSION}

An academic institution must create harmony between business and IT, the implementation of EA is a solution to developing information technology (IT) by promoting affectivities, efficiency, accountable, user-friendly, familiar, and real-time. The TOGAF ADM framework method can be applied in the UGK specifically, to support IT implementation that is in line with business processes, and produce blueprints for business architecture, data, applications, and technology. The suggestion in this study is to be able to continue the phases that exist in TOGAF $\mathrm{ADM}$, such as migration planning, implementation governance, and change of computer management. And it is expected to be able to use other diagramming approaches in TOGAF ADM so that it will add references to readers especially in terms of using existing diagrams.

\section{ACKNOWLEDGMENT}

This research is fully supported by UGK (Universitas Gunung Kidul) by allowing interviews and observation opportunities. Thank you for allowing the result of observations to be made into academic papers and published. This research and publication were funded and fully supported by Masters of Informatics Engineering of UAJY (Universitas Atma Jaya Yogyakarta).

\section{REFERENCES}

[1] J. W. Ross, "Center for information systems Massachusetts Institute of Technology Creating a Strategic IT Architecture Competency : Learning in Stages," 2003.

[2] P. Malyzhenkov and M. Ivanova, "An Enterprise Architecture-Based Approach to the IT-Business Alignment: An Integration of SAM and TOGAF Framework," pp. 159-173, 2017.

[3] G. F. Nama and D. Kurniawan, "An Enterprise Architecture Planning for Higher Education Using The Open Group Architecture Framework ( TOGAF ): Case Study University of Lampung," 1981.

[4] V. Goepp and M. Petit, "Insight from a comparison of TOGAF ADM and SAM alignment processes ScienceDirect," IFAC-PapersOnLine, vol. 50, no. 1, pp. 11707-11712, 2017.

[5] J. P. Meneses-ortegon and R. A. Gonzalez, "Knowledge Management Framework for Early Phases in TOGAF-based Enterprise Architecture," vol. 3, no. Ic3k, pp. 31-40, 2016.

[6] A. M. Drivers and G. Implementation, "Desinge and Implementation of Government Cloud Computing Requirements : TOGAF," 2017.

[7] B. D. Rouhani, M. Naz, F. Nikpay, M. K. Najafabadi, and P. Nikfard, "A Framework for Evaluation of Enterprise Architecture Implementation Methodologies," vol. 9, no. 1, pp. 1-6, 2015.

[8] A. Cabrera, M. Abad, and D. Jaramillo, "Definition and implementation of the Enterprise Business Layer through a Business Reference Model , using the architecture development method ADM- TOGAF," Trends Appl. Softw. Eng., 2016.

[9] C. M. Firmansyah and Y. Bandung, "Designing an Enterprise Architecture Government Organization Based on TOGAF ADM and SONA," 2016.

[10] S. Kotusev, "The Critical Scrutiny of TOGAF Is TOGAF a Consistent Methodology or Just a Toolkit?," no. April, pp. 1-9, 2016.

[11] U. De Lisboa, "Enterprise Architecture," pp. 257266, 2017. 
[14] I. L. Sardi and K. Surendro, "Rekomendasi Perancangan Arsitektur Enterprise Pascamerger (Studi kasus : Universitas Telkom)," vol. 1, no. February, pp. 61-76, 2016.

[15] Y. Dorohyi et al., "Cybersecurity and critical infrastructure protection," vol. 5, no. December, 2017.
[13] C. Rogers, "Proposed Enterprise Architecture solutions for Industry 4 . 0 Manufacturing simulation information assets based on TOGAF," no. August, 2016.
[12] T. R. Sari and E. Rahmawati, "TOGAF ADM to Prove the Promotion of Farm Edu-Tourism in Pondok Rangon Area," vol. 3, no. 2, pp. 280-287, 2019. 